\title{
An overview report on the situation of elderly people in urban and rural China: 2000-2015
}

\section{Yu Fang ${ }^{1}$ (D) Haitao Wang ${ }^{1} \cdot$ Zheng Ouyang $^{1}$}

Received: 20 May 2018 / Accepted: 18 September 2018 / Published online: 9 October 2018

(c) Springer Nature Singapore Pte Ltd. 2018

\begin{abstract}
China had become a country with an aging population by the end of the 20th century. Dealing with the aging of its population is a long-term strategic task for China. "The National Survey on Elderly People in Urban and Rural China" has been carried out four times since the year 2000. The data shows that during the years 2000 to 2015 the wellbeing of elderly people in urban and rural China improved greatly. The economic status of the elderly has obviously improved; and there have also been steady improvements to social security protections, health care services and the availability of social activities in which the elderly can participate. In addition, the spiritual and cultural life of the elderly has become richer and more colorful. The aging of society creates challenges, such as potential shortages of labor resources, the weakening of family functions and the need for more medical care facilities and services, and these intensify over time. At the same time, changes to the structure of demand and of industry caused by societal aging bring many opportunities.
\end{abstract}

Keywords Elderly people · Population aging · The National Survey on Elderly People in Urban and Rural China

Yu Fang

winniefangyu997@163.com

Haitao Wang

seaseas@163.com

Zheng Ouyang

rainyoyz@163.com

1 Research Division on Aging Strategy, China Research Center on Aging, Room 810, Zhongcai Dasha, No.48 Guanganmen Nanjie, Xicheng District, Beijing 100054, China 


\section{Introduction}

China has the world's largest aging population with more than 200 million elderly people. ${ }^{1}$ What can be said about the age structure and regional distribution of this population, their income and expenses, health care situations and opportunities for social participation, and other circumstances affecting the lives of these people? China's economy has developed rapidly in recent years. Have elderly people shared in the benefits that have come with economic and social development? Have their quality of life, their wellbeing and their sense of fulfillment improved? Systematic, in-depth research is urgently needed to answer these questions.

Research into the situation of elderly people began internationally in the 1970s, while research of this kind began in China in the 1980s. Research on the elderly focuses mainly on several aspects. First, it examines specific groups of elderly people, e.g. the oldest old, ${ }^{2}$ the rural elderly, the poor elderly, empty-nest elderly and left-behind elderly. The oldest old often lead lives that lack adequate economic support, daily care, medical security and spiritual consolation (Wang and Deng 2007). In urban areas, the situation of the poor elderly is generally not encouraging: their income levels are low and they cannot make ends meet; consequently, they have a very low material standard of living and this directly affects their health status, spiritual life, family relationships, life satisfaction, tolerance capacity and other life concerns (Chen 1999). The rural elderly have very limited sources of income and their income level is generally low; they expect little from life, but their life satisfaction is high (Han and Hou 2009). Among the groups of vulnerable elderly people, the widowed elderly are especially vulnerable. In rural areas, the spiritual life of the widowed elderly and the factors that impact spiritual life deserve more attention (Wang 2013).

Second, there are studies of the elderly in particular regions. For example, the elderly in Beijing, Shanxi, Hunan, Shandong or other regions are taken as the research objects. On the basis of their research into the situations of elderly people in particular areas, some scholars, such as Liao, Chen $(1998,1999)$ and Xu (2015), have proposed social support and community care programs. Xu (2015) examined four aspects of the living situations of the elderly in some communities in Beijinggeneral life situation, personal situation, family status and community environment.

Third, research has focused on elderly life from a particular perspective. Such research has achieved good results and has considered a wide range of topics, such as how the psychological needs of the elderly are satisfied (Li and Zhang 1997), the status of and changes to the self-care ability in daily life of elderly people as they age (Du and $\mathrm{Wu} 2006$ ), the health status of the elderly ( $\mathrm{Du} 2013$ ), and the level of social participation of the elderly (Li 2009).

Fourth, some Chinese scholars have looked at the elderly in other parts of the world or undertaken comparative studies. Lan (2004) did country-specific research,

\footnotetext{
1 In this report, the term "elderly people" and "the elderly" denote people aged 60 years or over.

2 In this report, the terms "young old", "very old" and "oldest old" denote people aged 60-69, 70-79 and 80 years of age and older, respectively.
} 
analyzing the elderly in Russia. There have been comparative studies comparing the status of elderly people in Yanbian, China, and South Korea (Jiang and Quan 2001), as well as a study of the elderly in urban areas in China and South Korea (Jin and Wang 2010).

Existing research on the status of elderly people has two common characteristics. First, studies generally lack an overall view of the situation. They are focused on specific age groups, specific regions or specific aspects of elderly populations. Second, there is a lack of comparative analysis, of either horizontal or vertical comparisons. This report tries to enrich the research on the status of elderly people in China from a vertical perspective, showing the main changes that have occurred among Chinese elderly people during the 15 year period from 2000 to 2015 . The data presented in this report can be used as the basis for scientific research on aging and for other types of social sciences research. The findings here can also help give policy makers, researchers, and people working in fields providing services to the elderly a better understanding of elderly people in China.

\section{Data sources}

The data used in this report are drawn from four surveys conducted by the China Research Center on Aging in 2000, 2006, 2010 and 2015 (Table 1). The four surveys were given different project names, but in this report for the sake of convenience, we have used a single name, "The National Survey on Elderly People in Urban and Rural China." We also refer to the four surveys as the 1st survey (2000), 2nd survey (2006), 3rd survey (2010) and 4th survey (2015).

Although all of the four surveys were conducted nationwide, they had different sample sizes and research designs. The 1st survey was a sampling survey, and the samples from this survey were traced by the 2nd survey in 2006 and the 3rd survey in 2010. If samples could not be traced for some reason (e.g. poor health, death or refusing the interview), new samples were taken instead. The 4th survey used a new research design that was different from the previous three surveys. Its geographical scope expanded from 20 to 31 provinces and the sample size increased to 220,170. Moreover, the questionnaires were not identical (Table 2). There were four questionnaires and each on was somewhat different than the others. Comparatively speaking, there were relatively small differences in the first three questionnaires, but the 4th questionnaire was considerably different than the previous three.

Although the questionnaires used, the geographical scope, and the sample size were different in the four surveys, the samples used by the surveys were nationally representative. Table 1 shows an overview of the four surveys. In this paper, we present data from the 2000 and 2015 surveys only. We chose to do this for two reasons. First, for the sake of brevity, and second, because the data in 2000 and 2015 are more readily comparable than data from the other two surveys. The wellbeing of elderly people has improved with the overall development of Chinese society. The greater the time span between the points of comparison, the more obvious the improvement is. 


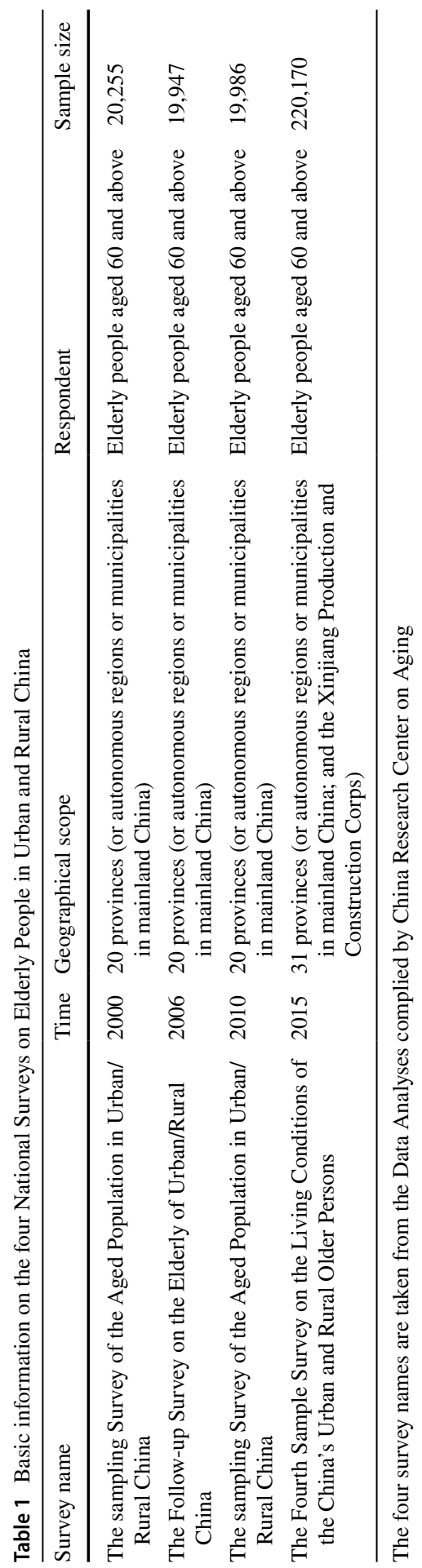


Table 2 The questionnaire content of the four National Surveys on Elderly People in Urban and Rural China

\begin{tabular}{|c|c|}
\hline Survey name & Summary of the questionnaire content \\
\hline $\begin{array}{l}\text { The Sampling Survey of the Aged Population in } \\
\text { Urban/Rural China }\end{array}$ & $\begin{array}{l}10 \text { parts: basic situation; employment; income; } \\
\text { housing; community service; economic status; } \\
\text { daily life; health and medical treatment; psycho- } \\
\text { logical status; observation record }\end{array}$ \\
\hline $\begin{array}{l}\text { The Follow-up Survey on the Elderly of Urban/ } \\
\text { Rural China }\end{array}$ & $\begin{array}{l}10 \text { parts: basic situation; employment; income; } \\
\text { housing; community service; economic status; } \\
\text { daily life; health and medical treatment; psycho- } \\
\text { logical status; observation record }\end{array}$ \\
\hline $\begin{array}{l}\text { Survey of the Aged Population in Urban/Rural } \\
\text { China }\end{array}$ & $\begin{array}{l}10 \text { parts: basic situation; employment and invest- } \\
\text { ment; income, expenditure and social security; } \\
\text { housing, facilities and environment; community } \\
\text { service and participation; family, living arrange- } \\
\text { ment and social network; health, ADL, IADL and } \\
\text { care need; health services and medical security; } \\
\text { psychological status and perception; observation } \\
\text { record }\end{array}$ \\
\hline $\begin{array}{l}\text { The Fourth Sample Survey on the Living Condi- } \\
\text { tions of China's Urban and Rural Older Persons }\end{array}$ & $\begin{array}{l}10 \text { parts: basic situation; family situation; health and } \\
\text { medical treatment; care services for the elderly; } \\
\text { economic status; housing and environment; social } \\
\text { participation; safeguarding of rights; spiritual and } \\
\text { cultural life; afterword }\end{array}$ \\
\hline
\end{tabular}

The data from the 2000 and 2015 surveys cover many aspects, but not all the data were suitable for use in a longitudinal study such as this one. As a result, we choose several major indicators in 2000 and 2015 to compare. This report on the overall situation of elderly Chinese people considers these factors: basic situation; socioeconomic status; health, medical treatment and care services; family and living arrangements; social participation and leisure activities. Finally, there is a discussion section at the end of this report.

\section{Basic situation}

The overall trend of change for the elderly population is positive. During the years 2000 to 2015 covered in this report, the proportion of elderly people to total population in China has increased steadily in recent years, and the situation with respect to elderly people has become more and more complex. The proportion of elderly people aged 60 and above rose from $10.5 \%$ in 2000 to $16.2 \%$ in 2015 and the total population of elderly people increased from 134 million to 222 million during those years. However, the age structure of the elderly population remains relatively young; the proportion of the oldest old to the total elderly population is not high. This suggests China has a window of opportunity to explore suitable means to deal with population aging. 


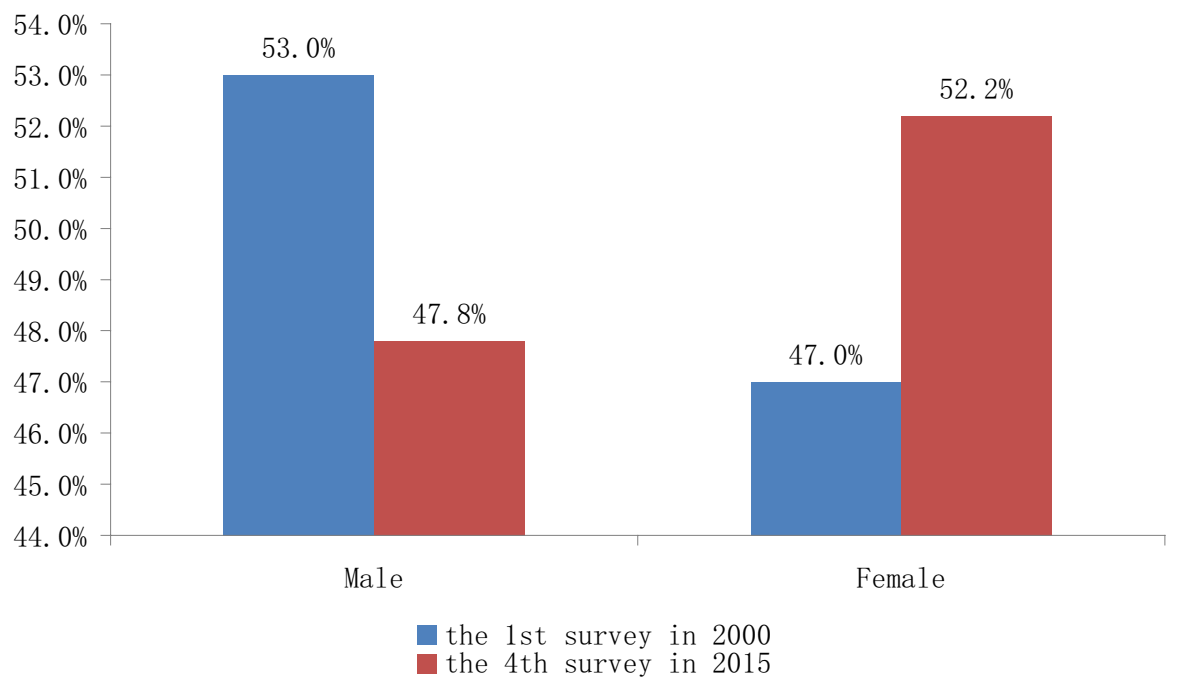

Fig. 1 Comparison of the proportion of the elderly male and female populations in urban and rural China in 2000 and $2015(\%)$

Fig. 2 The age structure of the elderly population in $2015(\%)$

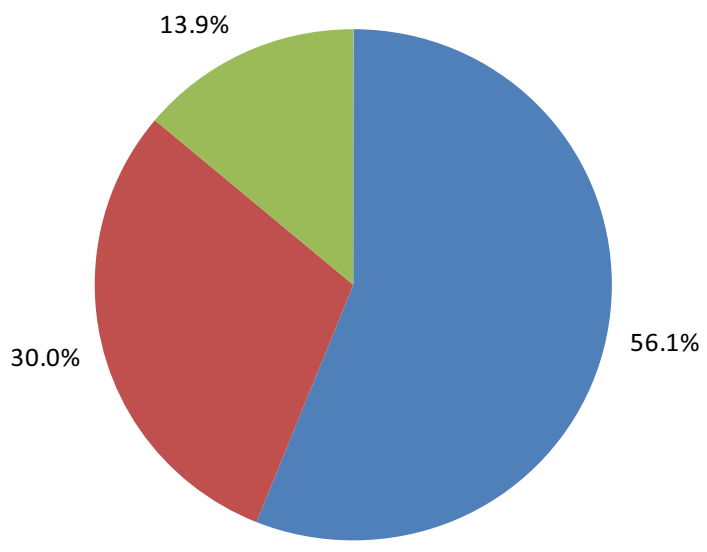

60-69 70-79 80+

\subsection{The proportion elderly females was higher than that of elderly males in $\mathbf{2 0 1 5}$}

The proportion of the elderly female population to the total elderly population is increasing steadily. Our investigation showed that in 2015 elderly females accounted for $52.2 \%$ of the elderly population in China, 4.4 points higher than the elderly male population that accounted for $47.8 \%$ of the total. The proportion of elderly females in 2015 increased by 5.2 percentage points as compared to the year 2000 when elderly females accounted for $47.0 \%$ of the total elderly population. As China's 


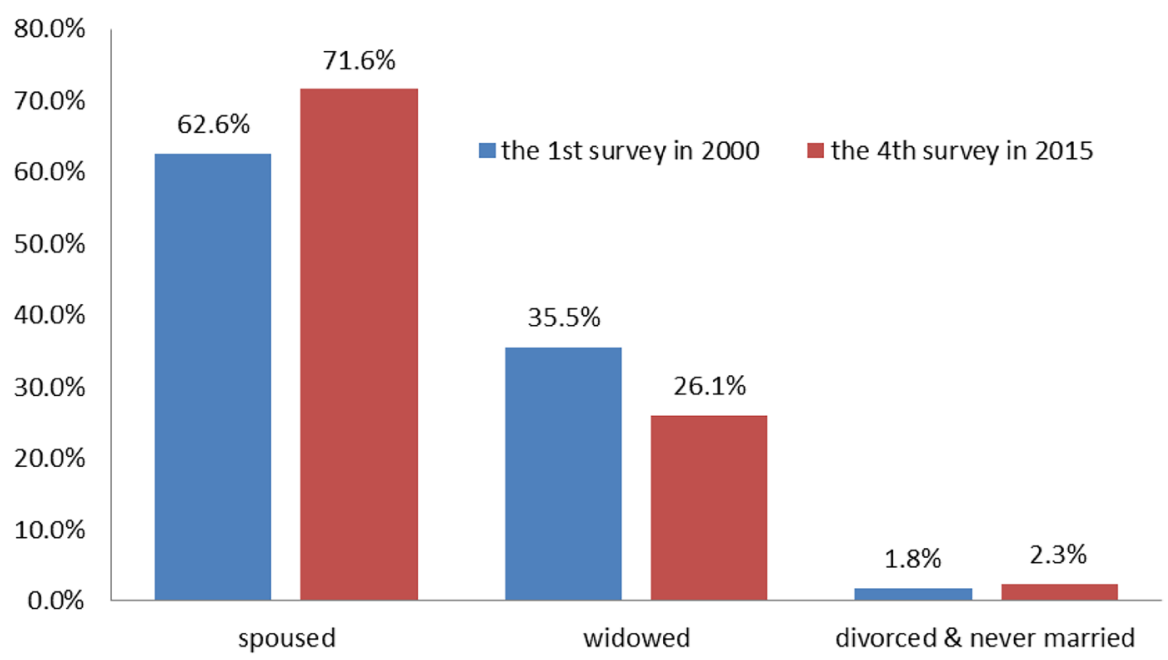

Fig. 3 Comparison of the marital status of the elderly population in 2000 and 2015 (\%)

population ages, the proportion of female elderly is gradually expanding. China's experience with respect to the increasing proportion of elderly females is consistent with the experiences of other aging societies (Fig. 1).

\subsection{The age structure of the elderly population was relatively young in 2015}

The 4th survey in 2015 showed that the proportions of elderly people aged 60-69, $70-79$, and 80 and above were $56.1 \%, 30.0 \%$, and $13.9 \%$, respectively, of the total elderly population (Fig. 2). In recent years, the speed at which China's population is aging has increased steadily, but in terms of the internal age structure of the elderly population in 2015 , the proportion of the young old $^{3}$ remained greater than $50.0 \%$, while the proportion of the oldest old was $13.9 \%$. This indicates that the age structure of China's elderly population is relatively young. In the 13th Five-Year Plan period (2016-2020), China will continue to respond to the aging of the population with strategic initiatives.

\subsection{More than $\mathbf{7 0 . 0 \%}$ of elderly people had spouses in $\mathbf{2 0 1 5}$}

The proportion of the elderly population that is widowed has decreased slightly. The 4th survey showed that in $201571.6 \%$ of the elderly population had spouses, a rise of 9.0 percentage points compared with the 1st survey in 2000 . The widowed elderly population accounted for $26.1 \%$ of the total elderly population in the 4 th survey,

\footnotetext{
${ }^{3}$ In this report, the terms "young old", "very old" and "oldest old" denote people aged 60-69, 70-79 and 80 years of age and older, respectively.
} 


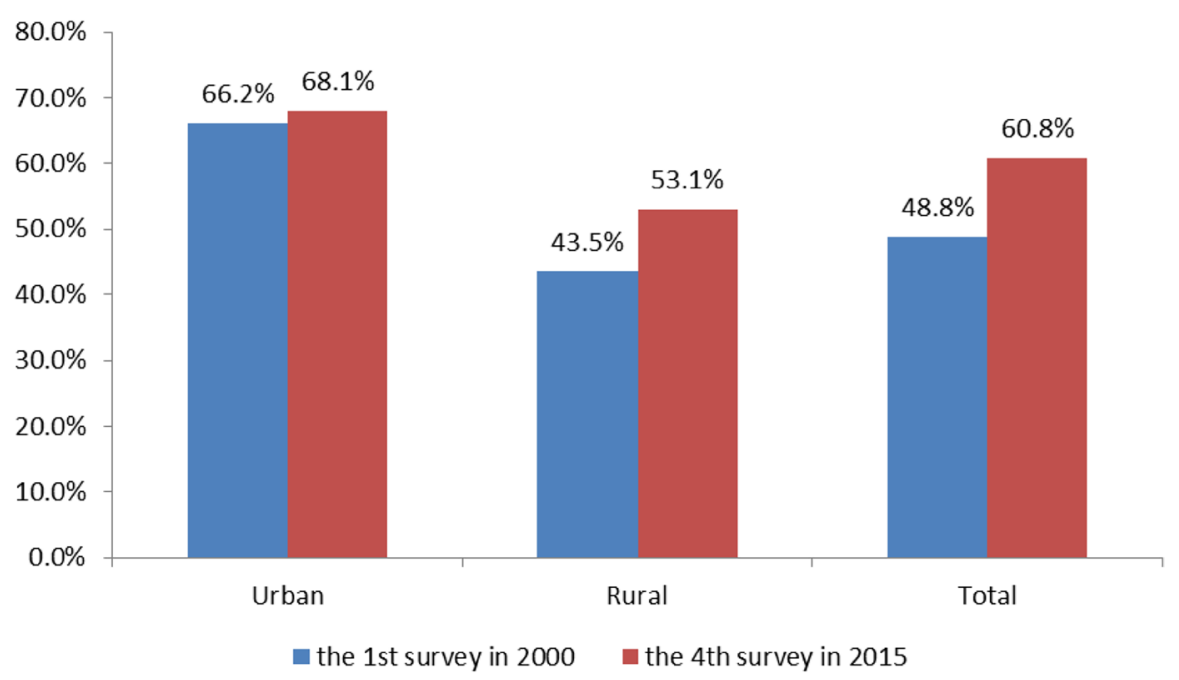

Fig. 4 The proportion of the elderly feeling happy in urban and rural China in 2000 and 2015 (\%)

dropping by 9.4 percentage points, and the divorced and never married population accounted for $2.3 \%$, increasing by 0.5 percentage points (Fig. 3 ).

\subsection{The proportion of elderly people "feeling happy" increased in rural China in 2015}

The 4th survey in 2015 indicated that $60.8 \%$ of the elderly population "feel happy" (This was a subjective evaluation based on answers to the question: "In general, do you feel happy?"), rising by 12.0 percentage points compared with the 1 st survey. The proportion of the elderly population feeling happy accounted for $68.1 \%$ in cities and towns, rising by 1.9 percentage points compared with the 1 st survey, and the proportion of the elderly population feeling happy in rural areas accounted for $53.1 \%$ of the rural elderly population, increasing 9.6 percentage points compared with the 1st survey in 2000 (Fig. 4).

During the years 2000 to 2015, the wellbeing of elderly people in China improved markedly. These years have featured rapid economic development in China and, thanks to the great efforts of the government, systems for social security and for the provision of health care and other care services for elderly people have been reformed, and elderly people, especially those from rural areas, have experienced great changes in their lives. Although China lacks experience and there is no mature international model to build on; nonetheless, after almost 20 years of exploration, we have made great progress and elderly Chinese have experienced steady improvements to their living standards. 


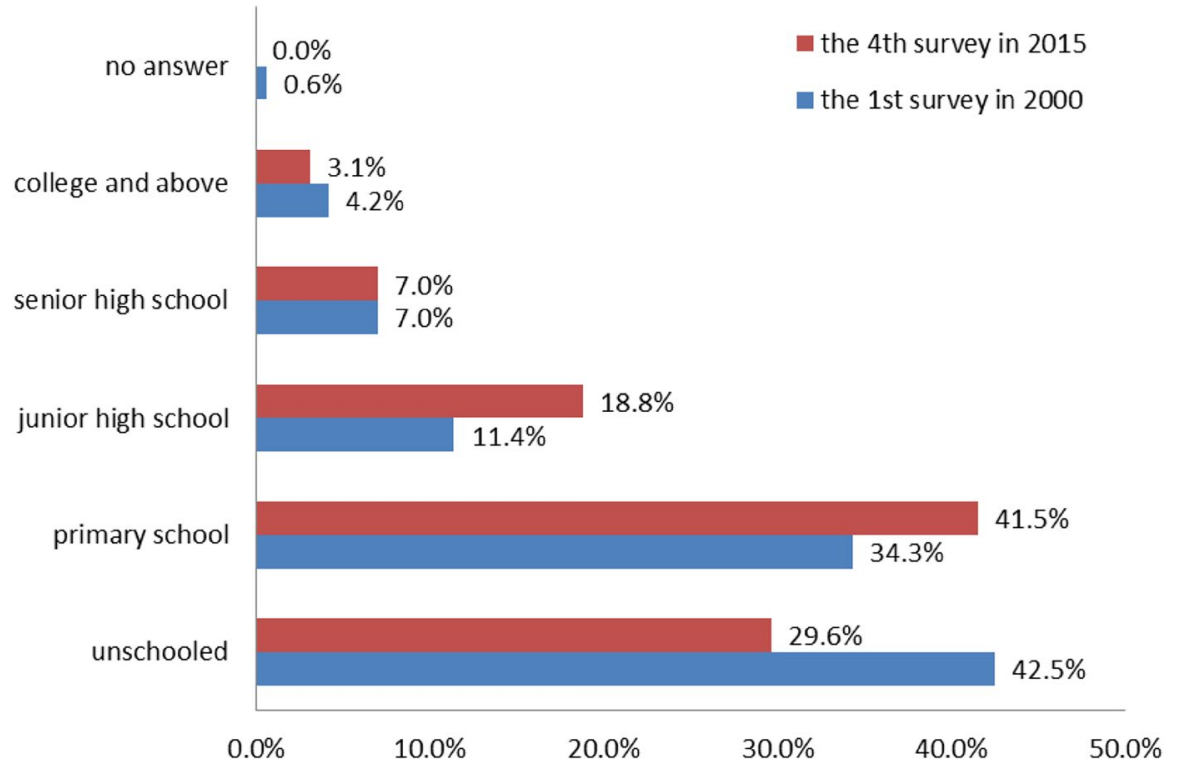

Fig. 5 Comparison of the educational levels of the elderly population in 2000 and 2015 (\%)

\section{Socioeconomic status}

\subsection{The educational level of the elderly has increased substantially}

The education level and economic status of elderly people have improved significantly. The education levels of the elderly in China rise as middle-aged people age and enter the ranks of the elderly. Education is extremely important to Chinese culture and with the development of education in recent years; the Chinese people are becoming more and better educated. People born in the 1950s, for example, have significantly higher education levels than those born in the 1940s. The 4th survey in 2015 showed that $29.6 \%$ of elderly people were unschooled, 41.5\% had primary school education, $18.8 \%$ had junior high school education, $7.0 \%$ had senior high school education and $3.1 \%$ had college or above education.

The educational levels of the elderly population reported in the 4th survey had increased substantially compared with the 1 st survey in 2000. The 4th survey in 2015 showed that the unschooled elderly population in China accounted for $29.6 \%$, a drop of 12.9 percentage points from the 1st survey. The elderly population with primary school education was $41.5 \%$, a rise of 7.2 percentage points from the 1st survey. In the 4th survey, the population with junior middle school and high school education accounted for $25.8 \%$, a rise of 7.4 percentage points, and the population with college degrees or above accounted for $3.1 \%$, dropping by 1.1 percentage points (Fig. 5). 


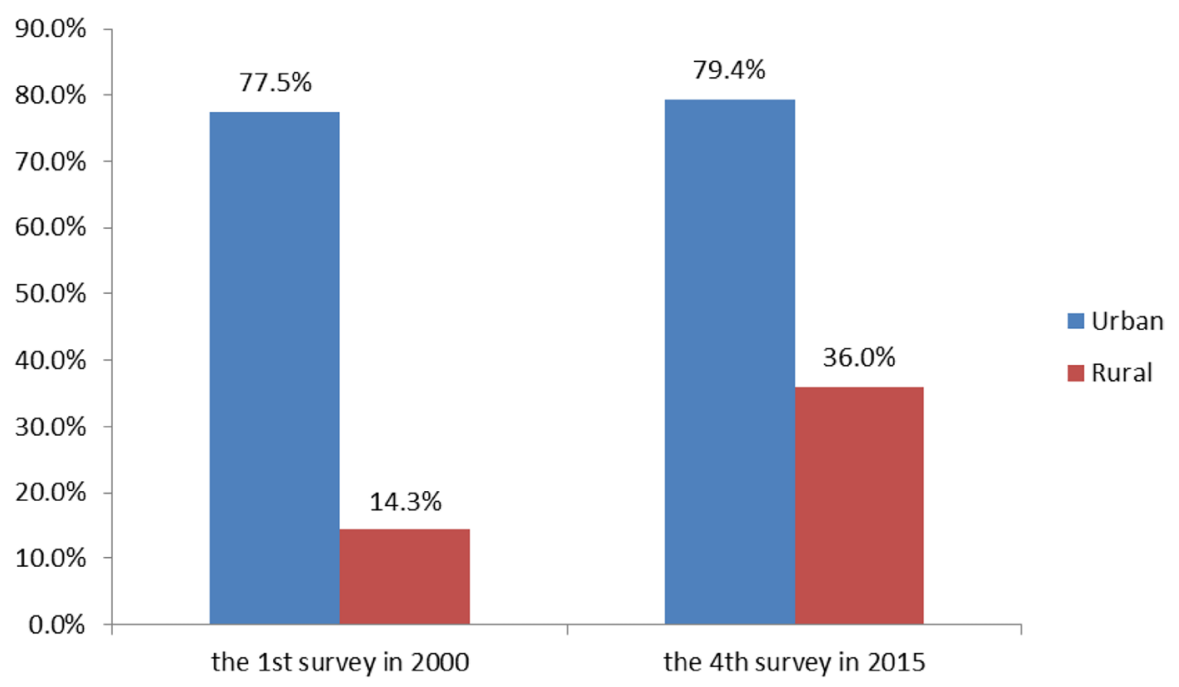

Fig. 6 Comparison of the proportion of guaranteed income to overall income for the elderly in urban and rural China in 2000 and $2014(\%)$

\subsection{The income levels of elderly people have risen}

During the years covered in this report, average per capita income for the elderly was not high, relative to average per capita income for the overall population. The 4th survey showed that in 2014 the average per capita income for the elderly in cities and towns was CNY 23,930 per year and was CNY 7621 per year for the elderly in rural areas. There are great differences between the income structures of the urban and rural elderly. The 4th survey showed that the main source of income for the urban elderly was guaranteed income, ${ }^{4}$ accounting for $79.4 \%$ of total income. The proportion of commercial income, ${ }^{5}$ income from property, family transfers and other non-guaranteed sources was $20.6 \%$. The 4th survey showed that the guaranteed income of the rural elderly had increased by 21.7 percentage points over the level shown in the 1 st survey, but the proportion of guaranteed income to overall income was only $36.0 \%$ for the rural elderly (Fig. 6). The level of access the rural elderly have to social welfare benefits remains relatively low.

The consumption structure of elderly people changed during the 15 year study period. In 2014, average per capita consumption expenditures of the elderly in urban and rural areas was CNY 14,764. The three principal categories of expenditures were ordinary living expenses, non-recurring expenditures and medical expenditures, accounting for $56.5 \%, 17.3 \%$ and $12.8 \%$, respectively, of total consumption. Compared with expenditures in the year of 2009 , the ratio of daily living expenses

\footnotetext{
${ }^{4}$ In this report, the term "guaranteed income" mainly refers to pension, allowance, relief fund, and other social security fund income.

${ }^{5}$ In this report, the term "commercial income" mainly refers to interest revenue, shares, national bonds and other financial income.
} 


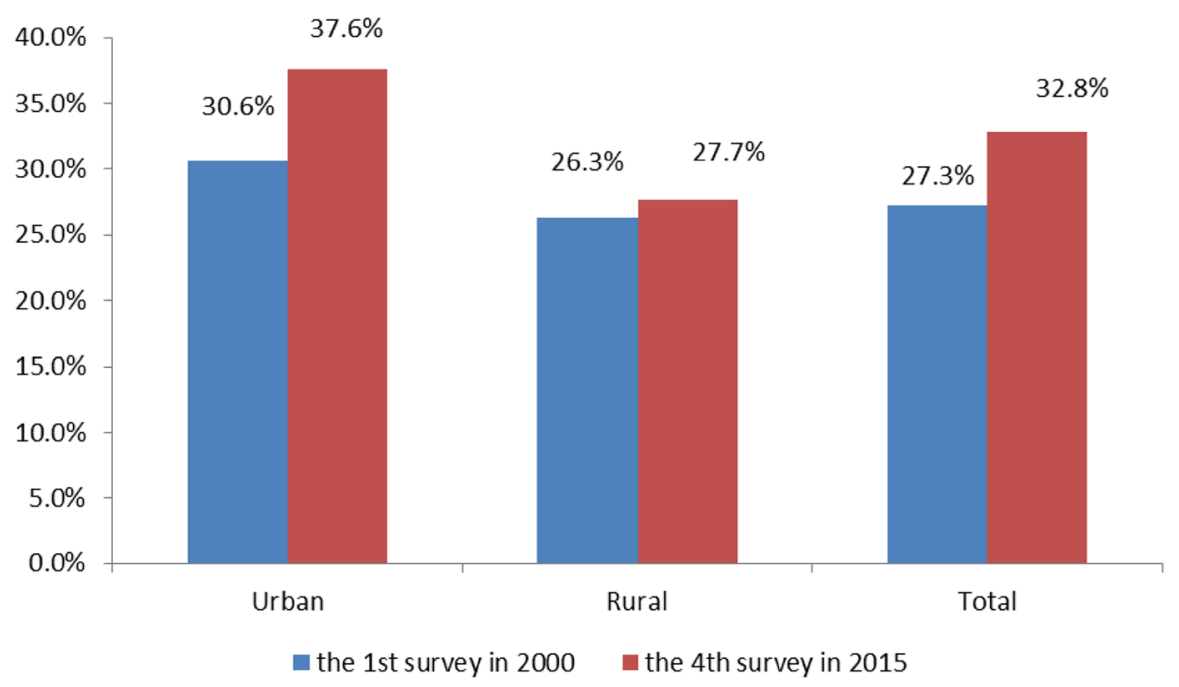

Fig. 7 The proportion of elderly self-evaluating their health as "good" in urban and rural China in 2000 and $2015(\%)$

and medical expenses was lower in 2014, while the proportion of non-recurring expenditures ${ }^{6}$ and expenditures on cultural activities increased.

\subsection{The elderly's self-evaluation of economic status was much better in 2015 than in 2000}

The results of the economic self-evaluation in 4th survey in 2015 (This was a subjective evaluation based on responses to the question, "What do you think of your financial situation?") were as follows: $1.3 \%$ of the elderly gave an assessment of very good, $14.8 \%$ said relatively good, $58.5 \%$ said enough or adequate, $21.2 \%$ said a little difficult, and $4.1 \%$ said very difficult. Generally speaking, the elderly's economic self-evaluation was much better in 2015 than in 2000.

In recent years, China has given a great deal of consideration to rural issues. Especially since the 18th Communist Party of China (CPC) congress (November 2012), the income of rural elderly people has increased significantly; its growth rate has been faster than that of income for elderly in cities and towns. The income structure of the urban elderly is becoming more diversified and increasingly optimal. Another change in the economic status of elderly people has to do with the steady increase in the consumption of cultural products and services. This means that, in addition to improvements in material conditions, elderly people are more able to participate in spiritual and cultural life. Nonetheless, the overall income level of the

\footnotetext{
${ }^{6}$ In this report, the term "non-recurring expenditures" mainly refers to one-time, nonrepetitive expenditure, such as house-purchase, car, furniture home appliances, gold \& silver jewellery, etc.
} 
elderly in urban and rural China is still relatively low, and the absolute numbers of poor and low-income elderly people are relatively large.

\section{Health, medical treatment and other care services}

\subsection{The elderly's self-evaluation of health in 2015 showed overall improvement}

The self-assessments elderly people made of their health (This was a subjective evaluation based on responses to the question, "How do you feel about your health?") improved on the whole in the 4th survey. In $201532.8 \%$ of the elderly answered "good" to the question, an increase of 5.5 percentage points over 2000. In urban areas, $37.6 \%$ of the elderly self-evaluated good health, a rise by 7.0 percentage points over 2000, and in the rural areas, $27.7 \%$ said they were in good health, an increase of 1.4 percentage points (Fig. 7).

There was only a relatively small increase between 2000 and 2015 in the percentage of rural elderly self-evaluating their health as good. The quality of medical treatment in rural areas is often poor to begin with, and many elderly people with limited financial resources in rural areas are reluctant to spend much money on medical treatment, even if they know they are ill. Especially in the case of minor ailments or chronic diseases, many elderly people choose to ignore the problem or procrastinate about seeking treatment. Moreover, in 2000 few rural elderly people were covered by medical insurance plans. Many rural elderly people seldom went to hospital and did not know they were ill or even if they suffered from a chronic disease. With the gradual improvement of the rural medical care system, the steady expansion of the rural cooperative medical insurance system and the rural elderly's increased awareness of health issues, the health status of the rural elderly will continue to improve slowly.

\subsection{China has achieved close to universal medical insurance coverage}

By the end of 2015, China's medical security system had developed to the point that virtually all Chinese were protected by medical insurance coverage. This suggests that China, the country with the largest population in the world, has realized a great leap in terms of providing medical security and public health services. The medical security system for the elderly has basically achieved full coverage. In 2015, the ratios of the elderly people enjoying medical security in urban and rural areas reached $98.9 \%$ and $98.6 \%$, respectively. During the year 2014, 56.9\% of the elderly in urban and rural areas enjoyed free medical examinations.

\subsection{The number of functionally frail elderly people is increasing}

The 4th survey in 2015 showed that $18.3 \%$ of the total elderly population or 40.63 million elderly people were functionally frail. The needs of these elderly 


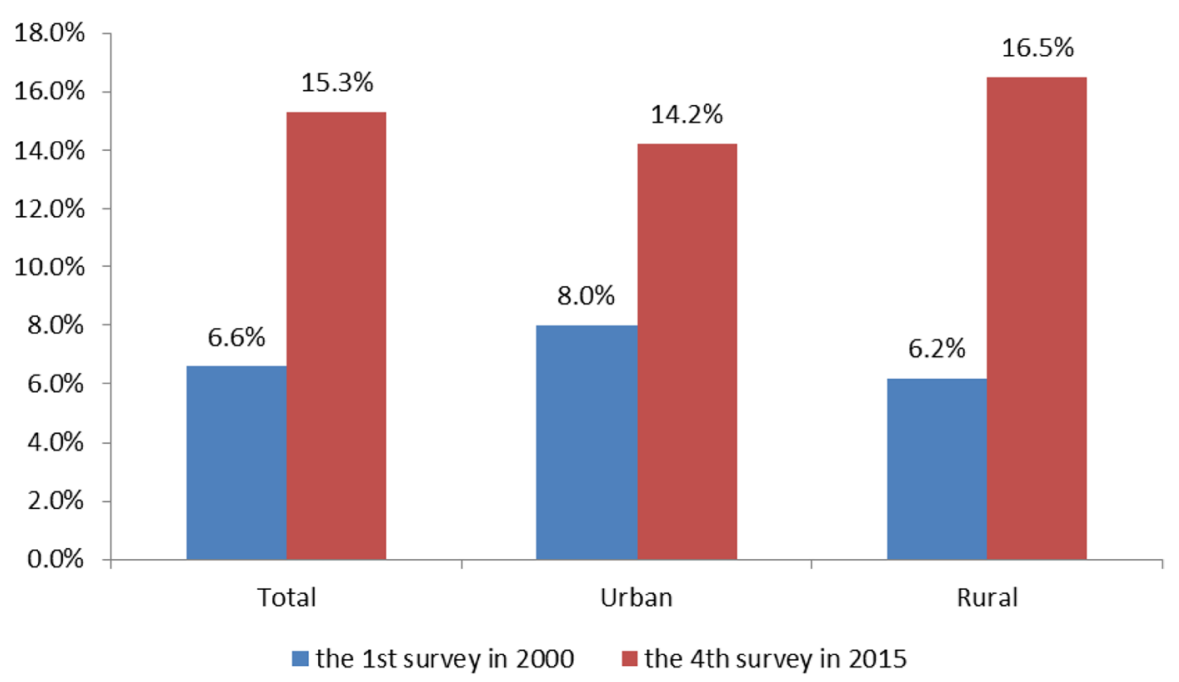

Fig. 8 Proportion of the elderly people reporting the need for assisted living services in urban and rural China in 2000 and $2015(\%)$

people for assisted living services have increased. In 2015, the proportion of the elderly who reported needing assisted living services was $15.3 \%$, an increase of almost 9.0 percentage points compared with 2000. In urban areas, the proportion of elderly people reporting the need for assisted living services increased by 6.2 percentage points, while in rural areas, the proportion rose by 10.3 percentage points (Fig. 8). The proportion of elderly needing assisted living services in the countryside increased faster than it did in cities and towns. Increasing numbers of functionally frail and empty-nest elderly people in China have urgent demands for care services. As the pace of China's urbanization process accelerates, in recent years some rural areas are being hollowed out, with young workers migrating to urban areas, leaving rural communities populated largely by left-behind elderly people and children. This explains the high demand for assisted living services in rural areas that existed between 2000 and 2015.

Looking at specific age groups of elderly, the proportion of elderly people aged 79 and below who reported a need for assisted living services increased from $5.1 \%$ in 2000 to $11.2 \%$ in 2015 , an increase of 6.1 percentage points over the 15 year period. The proportion of elderly people aged 80 and over needing assisted living services increased from $21.5 \%$ in 2000 to $41.0 \%$ in 2015 , a rise of nearly 20.0 percentage points and an increase more than 3 times greater than that of elderly 79 years old and below. It can be seen that the demand for assisted living services is urgent in urban and rural areas, especially the latter.

Among the demands for elderly care services in communities, house calls for medical consultations and rehabilitative nursing services are among the high priority needs for medical treatment and health care. The 4th survey in 2015 showed that $38.1 \%$ of the elderly needed doctor house call services, $11.3 \%$ needed rehabilitative nursing services, $9.4 \%$ needed day care services designed for the elderly, and 


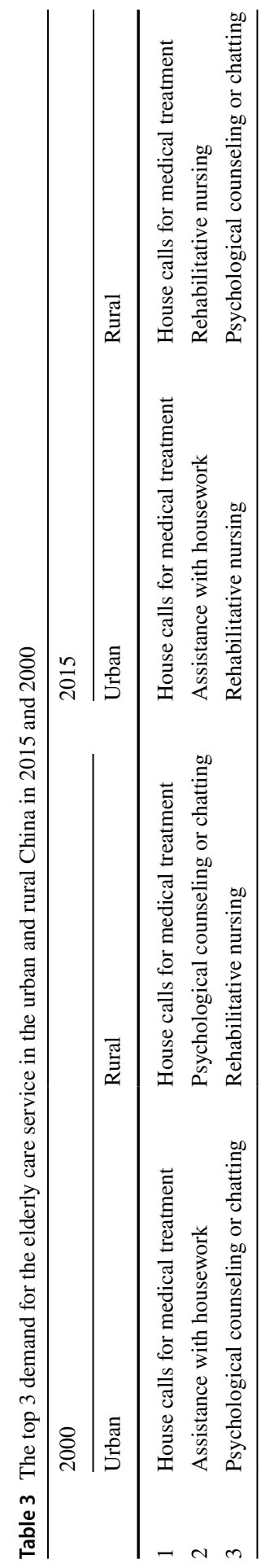




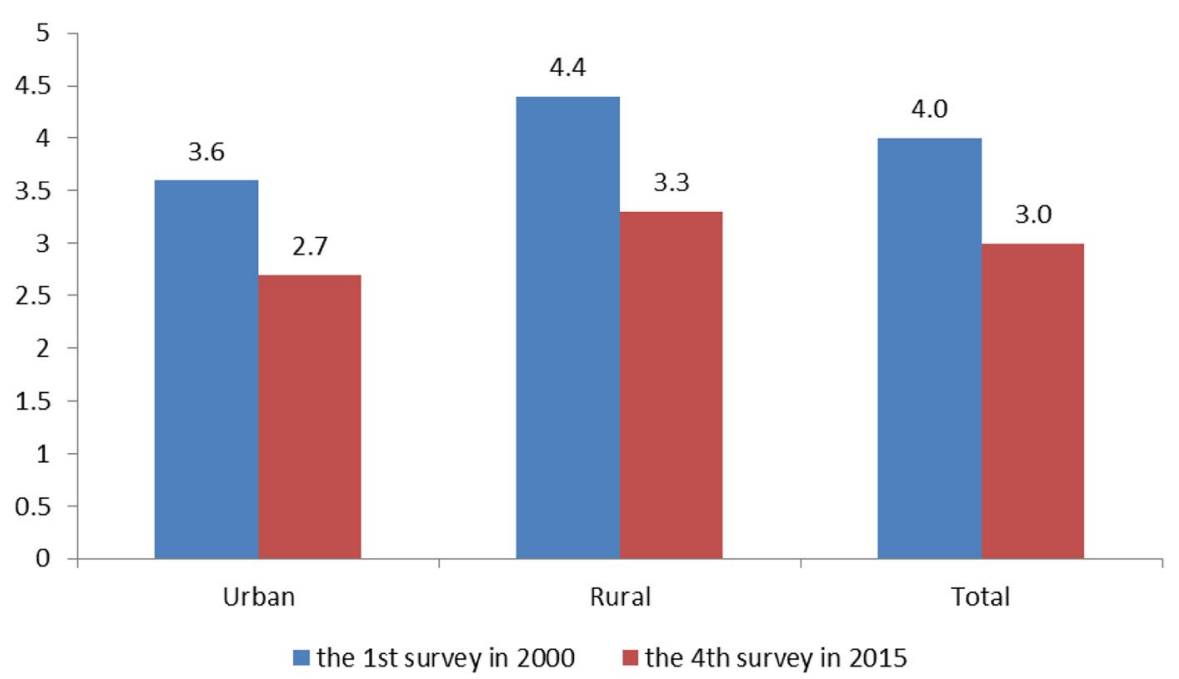

Fig. 9 Comparison of the average number of children of the elderly population in urban and rural China in 2000 and 2015 (person)

$10.3 \%$ needed health education services. Also, $12.1 \%$ needed assistance with housework, $10.6 \%$ needed psychological counseling or chatting services and $8.5 \%$ needed help preparing meals (Table 3). Thus, it can be seen that the combination of medical treatment and health care is an important direction of the future development of communities and home-based care services.

The market for providing services to elderly people has great potential, but there is an obvious imbalance between supply and demand. Over the 15 year study period, the proportion of the elderly who reported needing assisted living services has increased significantly. Moreover, elderly care services are also becoming more and more available as supply tries to keep pace with demand. This suggests that during the 15 years covered in this report, the market for elderly services in China has expanded steadily, and that the ideas China's elderly people have about consumption are constantly evolving.

\section{Family and living arrangements}

\subsection{Family size in China is shrinking}

The very old and oldest old have more children than the young old. ${ }^{7}$ According to the 4th survey in 2015 , the elderly had 3.0 children on average: the number of children was 2.7 in urban areas and 3.3 in the countryside.

\footnotetext{
${ }^{7}$ In this report, the terms "young old", "very old" and "oldest old" denote people aged 60-69, 70-79 and 80 years of age and older, respectively.
} 


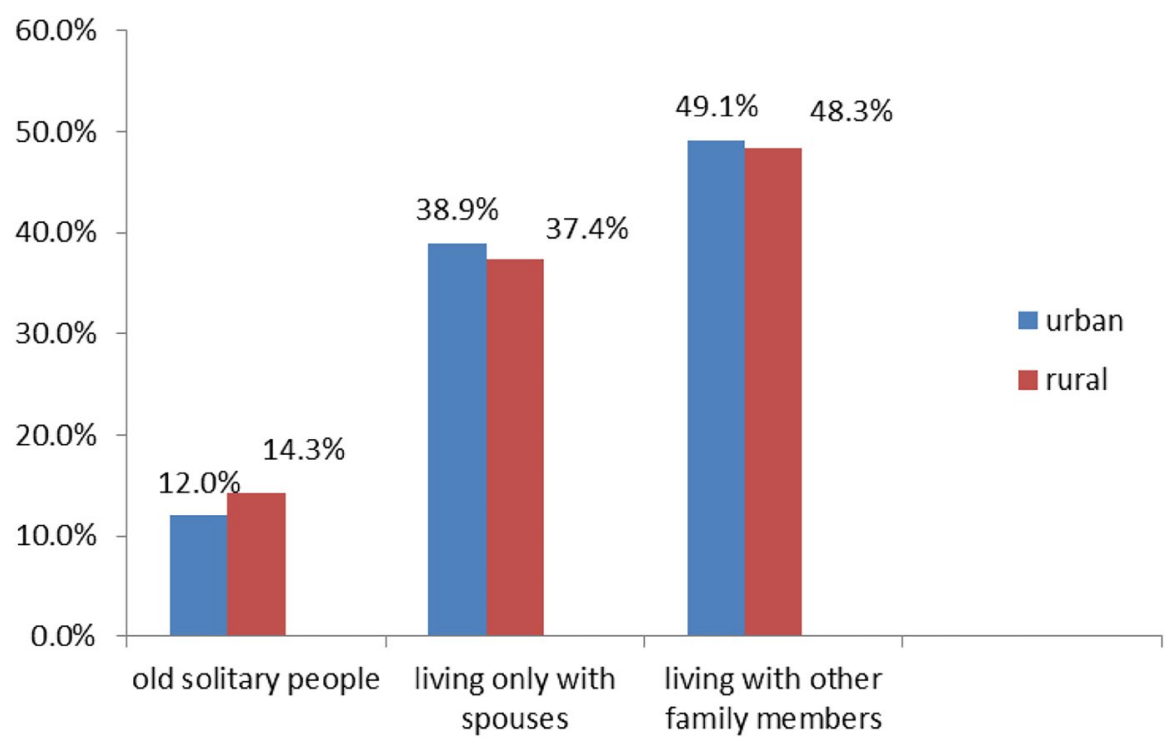

Fig. 10 The living arrangements of the elderly population in urban and rural China in 2015 (\%)

The 4th survey in 2015 showed that the average number of children of elderly people in the age groups 60-64, 65-69, 70-74, 75-79,80-84, and 85 and above were $2.3,2.7,3.3,3.7,4.0$ and 4.1 , respectively. This shows that the older the parents are, the more children they have. The decrease in average family size is probably an indication of the impact China's one-child family planning policy began to have in the 1980s. On average, the elderly in 2015 had one less child than the elderly in 2000 (Fig. 9). This decrease in the average number of children for the elderly means that the objective basis of the multi-generational family model has been seriously weakened; and this represents a serious challenge to the care function for elderly family members traditionally provided by the family.

\subsection{More than half of the elderly were empty-nest elderly in $\mathbf{2 0 1 5}$}

During the 15 years covered in this report, the number of empty-nest elderly has increased noticeably. On the one hand, this has been one result of the accelerated pace of China's urbanization process. On the other hand, social values and attitudes have changed, and more and more elderly people have chosen to live apart from their children to enjoy their own lives.

The 4th survey in 2015 found that empty-nest elderly people accounted for $51.3 \%$ of the elderly population. Single elderly people living alone accounted for $13.1 \%$, elderly people living with spouses accounted for $38.2 \%$, and elderly people living with family members other than their children accounted for $48.7 \%$. 
Generally speaking, the 4th survey found the living arrangements of elderly people in urban and rural areas were similar (Fig. 10). Empty-nest elderly people in cities and towns accounted for $50.9 \%$ of the total urban elderly population. Of this group, single elderly people living alone accounted for $12.0 \%$, elderly people living with spouses accounted for $38.9 \%$, and elderly people living with family members other than their children accounted for $49.1 \%$. In rural areas, empty-nest elderly people accounted for $51.7 \%$, with $14.3 \%$ living alone, $37.4 \%$ living only with spouses, and $48.3 \%$ living with family members other than their children.

The proportion of the empty-nest elderly people increased from $38.9 \%$ in the 1 st survey to $51.3 \%$ in the 4 th survey, a rise of 12.4 percentage points, and the proportion of elderly people living together with family members other than their children fell from $61.1 \%$ in the 1 st survey to $48.7 \%$ in the 4 th survey. These changes are mainly the result of urbanization and population mobility in recent years. In addition, people's living standards have improved steadily and social attitudes have changed. More and more elderly people are choosing to live separately if their physical and financial conditions have permit.

As the size of the average Chinese family decreases and the number of emptynest elderly continues to increase, China urgently needs to develop and perfect elderly care services. During the 13th Five Year Plan period (2016-2020) currently underway, China is working to optimize the elderly care service system built on a foundation of home-based care backed up by community-based care, and supplemented by institutional care that combines medical treatment with other care services. This is an outline of the overall institutional arrangements for China's elderly care services. The key point is to activate the family function and encourage the development of home-based care services, which are currently the weak link in these arrangements.

\section{Social participation and leisure activities}

\subsection{The participation rate of elderly people in community service activities has increased}

According to the 4th survey in 2015 , nearly half (45.6\%) of the elderly population participated in various kinds of community service activities. Relatively large proportions of elderly helped neighbors $(34.2 \%)$, took part in activities to maintain cleanliness and hygiene in their communities $(20.7 \%)$ or helped to mediate neighborhood disputes (17.0\%). In cities and towns, the participation rate in community service activities increased from $38.7 \%$ in 2000 to $43.2 \%$ in 2015 . During the 15 year study period, the participation rate of China's elderly in community service activities increased. Participation in such activities can enhance the self-esteem of elderly people and, at the same time, contribute to the harmonious and stable development of society. Elderly people are playing an important role in community construction and social governance. 
Table 4 Internet access and online activities of the elderly in urban and rural China in 2015 by age group and gender $(\%)$

\begin{tabular}{|c|c|c|c|c|c|c|c|c|}
\hline & \multirow[t]{2}{*}{ Total } & \multicolumn{2}{|c|}{ Urban and rural } & \multicolumn{2}{|c|}{ Gender } & \multicolumn{3}{|l|}{ Age } \\
\hline & & Urban & Rural & Male & Female & Young old & Very old & Oldest old \\
\hline Internet access rate & 5.0 & 9.1 & 0.5 & 6.6 & 3.6 & 6.8 & 3.4 & 1.6 \\
\hline News & 84.8 & 85.0 & 81.9 & 89.5 & 77.0 & 85.1 & 84.9 & 79.4 \\
\hline TV series & 35.0 & 34.6 & 40.7 & 32.1 & 39.8 & 36.8 & 30.8 & 26.7 \\
\hline Games & 27.2 & 28.2 & 13.3 & 25.1 & 30.6 & 28.4 & 24.6 & 18.7 \\
\hline Chat & 20.8 & 21.2 & 15.5 & 15.7 & 29.2 & 22.0 & 17.2 & 17.3 \\
\hline Stocks & 13.1 & 14.0 & 1.7 & 13.2 & 13.0 & 13.7 & 11.7 & 9.5 \\
\hline Shopping online & 11.9 & 12.4 & 5.4 & 10.1 & 14.9 & 13.1 & 9.3 & 5.8 \\
\hline
\end{tabular}

Most elderly people are willing to help their elderly peers. The 4th survey in 2015 showed that most (72.9\%) elderly people were prepared to help other elderly people who encountered difficulties in their communities. Elderly people aged 60-69 were the group most inclined to help other elderly people (78.0\%). This indicates that neighborhood mutual assistance activities have a good social basis. We can encourage those elderly people who are willing and able to serve their neighbors by taking part in efforts to provide home-based care.

\subsection{Associations for elderly people have developed rapidly in urban and rural China}

The development of associations for the elderly has great potential. According to the 4th survey in $2015,10.3 \%$ of elderly people took part in such associations. In cities and towns, the participation rate (11.0\%) in elderly associations was higher than that in rural areas (9.6\%), and the participation rate of elderly men (11.2\%) was higher than that of elderly women (9.5\%). As mass organizations allowing elderly people to undertake self-management, self-education and self-service, elderly associations in communities have played an important role in rallying and serving the elderly and in promoting the social participation of elderly people. The findings suggest that developing grassroots level associations for elderly people is a direction for community work. Elderly people cited several reasons for not joining elderly associations: no associations had been established in their community (44.9\%), they were not interested in joining an existing association (23.1\%), or they did not have time to join (21.8\%).

We should continue to establish associations for the elderly in communities, and at the same time, we should do more to promote these associations and build their capacity to effectively serve the elderly in urban and rural China. 


\subsection{Elderly people's leisure activities have become increasingly diversified}

The leisure activities of elderly people are mostly sedentary activities. The 4th survey in 2015 indicated that $88.9 \%$ of elderly people often watched TV or listened to the radio, $20.9 \%$ often read books or newspapers, $18.0 \%$ grew flowers or kept pets, and $13.4 \%$ often played chess or card games.

Compared with the 1st survey in 2000, in the 4th survey, the proportion of the elderly people playing chess or cards had decreased somewhat, while the proportion of elderly people participating in the other leisure activities had increased. On the whole, the leisure activities of elderly people continued to be mostly sedentary. This may be related to the physiological characteristics of elderly people: as they grow older, their physiological functions may degenerate. Sedentary leisure activities are acceptable to most elderly people because the activities are simple and move at a slow pace.

The proportion of elderly people who are connected to and use the Internet has increased. The 4th survey in 2015 showed that $5.0 \%$ of the elderly often surf the Internet, and this percentage was higher among the elderly groups in cities and towns and among the young old in urban areas, being $9.1 \%$ and $12.7 \%$ respectively (Table 4). The 1st survey in 2000 showed that only $0.3 \%$ of elderly people had learned to use a computer. A comparison of the 1st survey and the 4th survey shows the elderly's usage rate of the Internet increased greatly during the 15 years covered in this report. The likely reasons are: first, knowledge of the Internet and how to use it has become widespread among all Chinese including the elderly; and second, elderly people want to use the Internet because it helps them enrich their lives, keep up with the latest news and information, participate in social communications, and avoid feelings of loneliness.

The elderly's spiritual and cultural life in both urban and rural areas has kept pace with the times, while the mental health of the elderly is worthy of attention. During the 15 years covered in this report, years of rapid economic development and great social change, the spiritual and cultural life of the elderly in urban and rural areas became more diversified. In particular, as the education levels of elderly people have gradually improved, use of the Internet has become a new kind of leisure activity and a means of social contact for the elderly in urban and rural areas. In recent years, new industries providing services to the elderly, such as elderly travel businesses and health maintenance facilities, have emerged. More and more elderly people have left home to travel, while their leisure activities at home have become more diverse and their spiritual and cultural lives more colorful. Moreover, elderly people have begun to participate actively in community service activities, and their power to benefit the public cannot be ignored. They also actively participate in community construction, help each other, and make contributions to the society with their knowledge, skills and experience.

However, we must be sure to pay sufficient attention to the mental health of the elderly population. In China, there is little awareness of the spiritual counseling needs some elderly people have, and the level of services available is relatively low. There are occasional cases of suicide among the elderly people in rural areas, and the mental health problems of the left-behind elderly can be pronounced. At present, 
the number of empty-nest elderly has increased by more than half, and the state of their mental health deserves more attention.

\section{Discussion}

\subsection{Economic development and the urbanization process have affected the wellbeing of elderly people}

Since the reform and opening-up process began, China's economy has achieved remarkable development and the social security level of the population has improved steadily. China is in the preliminarily stages of setting up a suitable system for medical insurance and social security. As members of society, China's elderly people have actively participated in economic construction, and they have also shared in the improvement of living standards brought about by economic and social progress. The elderly have seen their incomes increase steadily, and the average life expectancy extended. The forms of social participation available to elderly citizens are rich and diversified, and their quality of life continues to improve. Thanks to China's rapid development in recent years, elderly people are one group of the population that can expect to live better and better.

\subsection{Elderly people have benefited from the promotion and optimization of systems to enhance the social security of citizens}

In recent years, China has responded with bold, innovative initiatives to meet the challenges created by an aging population. In particular, the third plenary session of the 18th CPC congress proposed "the establishment of a fairer and more sustainable social security system”. In 2015, China's basic medical insurance system had achieved full coverage. In the year 2000, less than $30.0 \%$ of Chinese people were covered by medical insurance. Since the period of The 12th Five-Year Plan (2011-2015), China has been developing an elderly care service system built on a foundation of home-based care backed up by community-based care, and supported by institutional care. Social welfare and social relief systems for the elderly have been regularly optimized, and family planning and family old-age security policies have been improved to offer more support. Educational, cultural and sporting activities for the elderly have developed rapidly, and spiritual and cultural life of China's elderly has become richer. In 2013, China's law for the protection of the rights and interests of the elderly was revised. This revision took protection of the legal rights and interests of the elderly a step further. It is, however, noteworthy that the fragmented nature of China's pension system results in problems and challenges that hinder further improvement of the living standards of the elderly in China's rural areas. 


\subsection{China's relatively young elderly population brings opportunities}

During the 15 years examined in this report, the proportion of elderly people to total population increased steadily, and the dependency ratio of the elderly also rose during this time. At present, the structure of China's aging population is relatively young, the educational level of the elderly today is higher than it was in the past, and the proportion of widowed elderly has dropped significantly. The very old and oldest old elderly have more children than the young elderly. They benefit from larger families that can maintain the traditional family support function. Overall, although Chinese society continues to age gradually, the relatively young structure of today's elderly population structure provides China with a window of about ten years to take advantage of strategic opportunities to cope with the challenges of population aging. Ways can be found for the whole society to deal reasonably with the huge demand for elderly support resources that result from population aging. We are in a position to alleviate the negative effects of population aging.

\subsection{The transformation of society's ideas about aging benefit elderly people}

As China's population grows and the rate at which the population is aging accelerates, the society's ideas about support for the elderly are being transformed into a new approach combining a variety of pension schemes with home-based care for the elderly. The elderly care service system built on a foundation of home-based care, backed up by community-based care, and supplemented by institutional care that combines medical care with other care services is gradually being optimized.

Traditionally, children are seen as providers and caregivers for their aging parents. Today, this traditional idea is being supplanted by a concept for elderly support that combines the joint efforts of the government and social forces. China is actively implementing positive strategies that support the aging of the population. Efforts begun in 2018 to educate the general public about population aging are resulting in increased awareness and understanding of the population aging process in China. We will take positive measures to defend the rights and interests of elderly people, and to improve the quality of life and enhance the wellbeing of the elderly in urban and rural areas.

\subsection{Despite a weak foundation, the industry for elderly products and services in China is growing}

In $2015,65.6 \%$ of the elderly population reported that they had used products for elderly people. As society develops and people's living standards improve, the market for elderly products will become further segmented and elderly products will need to meet more targeted, exacting demands. The market for elderly products and services has enormous growth potential. It is generally believed that 2013 was the year that policies began to support development of an industry for elderly products and services. It was in this year that the State Council issued several opinions on 
accelerating the development of the elderly care service industry. After that, a series of policies were introduced, and the industry began to flourish.

Currently, the development of businesses providing products and services to the elderly is unbalanced. In particular, the development of services for the elderly in rural areas started relatively late and has a weak foundation. The degree of population aging in China's countryside is greater than it is in cities and towns. Moreover, the government plays a dominant role in the provision of services to the elderly in both urban and rural areas, and this mode of supplying services is generally not responsive to the actual demands elderly people have for services. In fact, China's industry for elderly products and services has not yet developed to the point that it can easily adapt to the changing situation and needs of China's aging population.

\subsection{China is still facing many challenges caused by population aging}

Thanks to the joint efforts of the government, society and families, elderly people in urban and rural China are leading much better lives today than they did in the past. However, as the market economy continues to develop steadily in China, trans-regional flows of labor have intensified. In addition, as a result of the implementation of the one-child policy, the proportion of China's empty-nest families has gradually increased. This has shaken the foundation of support for the elderly provided by traditional families. Moreover, many rural laborers have migrated to economically developed areas, and this has intensified the empty-nest phenomenon in rural areas. Nearly half of the China's elderly people live in the countryside where, currently, social insurance protections are relatively limited. The society needs to pay more attention to the needs of rural elderly who can no longer participate in the labor force or become ill and need care.

\section{Conclusion}

Against a background of extensive socioeconomic change, the wellbeing of the elderly in urban and rural China has also greatly changed. Salient aspects of this change in the situation of the elderly include: the economic and health status of the elderly has significantly improved; the demand for elderly care services is growing steadily, there is an ongoing effort to promote the rights and interests of China's elderly, and the ability of elderly people to participate in spiritual and cultural activities has greatly expanded.

However, the problems and challenges caused by population aging combined with unbalanced economic and social development from region to region in China have also led to a growing gap between the situations of the elderly in urban and rural areas. The development of the industry for elderly products and services is uneven, and imbalances between supply and demand in this industry are still severe in some cases. The laws and regulations concerned with the support of the elderly population 
are flawed and efforts to strengthen the law lag. This results in obstacles that hinder the construction of living environments for elderly people. The status of the poor elderly and the functionally frail elderly is problematic. The aging of society creates problem and challenges that intensify over time. China currently faces potential shortages of labor resources, the weakening of family functions, and the need for more medical care services and services. At the same time, changes to the structure of demand and of industry caused by societal aging bring many opportunities.

\section{References}

Chen, C. (1998). The living situations of the aged in rural areas and their social support. Social Science Research, 6, 97-101.

Chen, C. (1999). Living situations and social support of the aged poverty-stricken citizens. Social Science Journal of Hunan Normal University, 4, 19-26.

Du, P. (2013). An analysis on the health status of the elderly in China. Population \& Economics, 6, 3-9.

Du, P., \& Wu, C. (2006). Ability of daily life of the Chinese elderly: Status and changes. Population Research, 1, 50-56.

Han, M., \& Hou, Y. (2009). The exploration and analysis of the living situations of the aged in rural areas and the supporting model for the aged in the countryside. Special Zone Economy, 8, 145-147.

Jiang, Y., \& Quan, H. (2001). Comparison: Living situations of the aged people in Yanbian area and Korea. Journal of Yanbian University (Social Science), 04, 35-38.

Jin, Y., \& Wang, X. (2010). Comparison research of senior living situations in cities between China and South Korea. Journal of Jilin Agricultural University, 1, 109-113.

Lan, Y. (2004). Study on the living situations of the elderly in Russia. Society., 12, 32-34.

Li, Z. (2009). The theoretical basis and path selection of the social participation of the elderly. Journal of Shandong Agricultural Administrators' College, 4, 92-94.

Li, J., \& Zhang, F. (1997). Study of mental health and related factors of urban elderly. Chinese Journal of Population Science., 3, 29-35.

Wang, B. (2013). A survey of the living situations for widowed old people in rural areas. Journal of Guizhou Minzu University (Philosophy and Social Science), 3, 79-83.

Wang, C., \& Deng, Z. (2007). The research on the living situations of senile people in urban society. Social Science Journal of Hunan Normal University, 3, 77-79.

$\mathrm{Xu}, \mathrm{H}$. (2015). The research on living situations of the elderly in old communities: Taking nine old people in $H$ communities, $C$ street, Beijing as an example (Master's thesis). Beijing: China Youth University of Political Studies.

Yu Fang received her doctorate in folklore from Graduate School of Chinese Academy of Social Sciences. Currently, she is an associate research fellow in the Research Division on Aging Strategy, China Research Center on Aging. Her research interests include anthropology of aging, cultural studies and community participation.

Haitao Wang received his doctorate in demography from Peking University. Currently, he, associate research fellow, is the chief of the Research Division on Aging Strategy \& Research and External Communications, China Research Center on Aging. His research interests include aging strategy, aging statistics and policy on elderly people.

Zheng Ouyang received her doctorate in social work from City University of Hong Kong. Currently, she is an associate research fellow in the Research Division on Aging Strategy, China Research Center on Aging. Her research areas include social gerontology, mental health, as well as human service management. 